\title{
Research on the Influence of Consumption Emotion on Participation Behavior
}

\author{
Hong Jin \\ School of Business, Jiangxi Normal University \\ Jiangxi, China \\ Guanghua School of Management, Peking University, \\ Beijing, China \\ 342944219@qq.com
}

\author{
Yunting Miao \\ School of Business, Jiangxi Normal University \\ Jiangxi, China \\ 771022025@qq.com
}

\begin{abstract}
Consumer emotion is an important reference factor for user decision-making. Researches have shown that consumer emotion is one of the important factors affecting consumer behavior. At the same time, participation behavior as an important behavioral variable is getting more and more attention. Although many controllable factors would trigger consumer emotion, previous studies mainly focused on the external factors such as product attributes, store environment, and the relationship between consumption emotion and satisfaction caused by external factors. In addition, there is some discussions about the relationship between consumer emotion and user engagement behavior. Based on this, this paper has combed the relevant literature on consumer emotion and mobile social network in detail. What's more, this paper also analyzes the impact of consumer emotion (positive emotions, negative emotions) on user engagement behavior. We hope that the conclusions of this study can help enterprises make full use of consumer's consumption emotion and enhance the participation of mobile network users.
\end{abstract}

Keywords-Positive emotions; Negative emotions;Participation behavior; Mobile social networks

\section{INTRODUCTION}

With the development of social networks, e-commerce and mobile platform, China is entering the era of quantitative consumption. The consumption, education, health, shopping and other consumer activities of consumers through the mobile network have caused tremendous changes in the consumer's consumption environment. This will inevitably affect consumer spending emotion. However, based on the new liquid consumption environment created by "Internet + " and big data, the changes and characteristics of consumer emotion in mobile social networks, and the impact of consumer emotion on consumer behavior have attracted the attention of industry scholars.

Therefore, this paper hopes to improve the research on the impact of consumer emotion on user participation behavior through literature review.

\section{LITERATURE REVIEW}

\section{A. Consumption Emotion}

The earliest research on emotions originated in psychology, and Leeper (1973) argued that emotion is a positive force with intuition and motivation. This power can organize, maintain, and guide behavior. Lazarus (1984) gives a definition of emotions: emotions are information from the environment that is going on, good or bad. It depends on a short-term or continuous evaluation that can cause an individual's physiological response. With people's understanding of emotions, scholars study emotion-related issues from the perspectives of education, medical care, and management (RE Sutton, KF Wheatley, 2003; Yao Jianglong, 2016; C Zimmerman, 1994; Cabeza, Roberto et al. 2007; Zhang Qing, Zhu Dixing, 2014; Han Liyan, Wu Yanran, 2007). Reviewing research on consumer emotion in marketing focuses on consumer emotion (PU Nyer, 1997; DM Phillips, H Baumgartner, 2002; R Ladhari, 2007; HS Han, KJ Back, 2008; C Xie, RP Bagozzi, K Grønhaug, 2015; Han Xiaowei, Wen Biyan, Wu Xiaoyu, 2004; Yan Lihui, Chen Shuqing, 2006; Chen Hui, Li Yuanzhi, 2007). The definition of consumer emotion in marketing is currently used by Westbrook and Oliver (1991) to define consumer emotion. They believe that consumer emotion refers to a series of emotions or feelings that consumers cause during the use or consumption experience of a product. This can be expressed in terms of unique emotional experiences (such as: happiness, anger and fear) or structural emotions (such as: happy/sad, relaxed/stressed, or calm/excited).

There are many different opinions on the division of consumption emotions. The two-dimensional theory proponent of emotions, Russell (1980), proposes a two-dimensional model of consumer emotion. Emotion is a continuous state formed by the opposite of "pleasant", "unpleasant", "evoked" and "quiet". The sophomore model that divides emotions into two dimensions of potency and awakening is currently more recognized. The three-dimensional theory of emotions represents the scholar Wundt (1896) who believes that emotions are composed of three dimensions, namely, pleasantunpleasant, agitated-quiet and nervous-relaxed. These are the foundations for scholars to study the dimensions of emotions. H Schlosberg (1954) divided emotions into happy-unpleasant, 
note-rejected, and awakened-free three dimensions, and based on these three dimensions established a three-dimensional pattern. Edell and Burke (1987) proposed that the dimensions of emotion have three dimensions: "encourage", "negative" and "warm". Plutchik (1980) argues that emotions have three dimensions of intensity, similarity, and bipolarity, using an inverted cone to explain the relationship of the three dimensions. American psychologist Izzard (1977) proposed the four-dimensional theory of emotions, which believes that emotions have four dimensions: happiness, tension, excitement, and certainty. Huang Xiting (2007), a domestic psychologist, believes that the nature of emotional experience can be divided into intensity, tension, pleasure, and complexity. According to the speed, intensity and duration of emotions, emotions can be divided into three categories: mood, passion and stress.

Reviewing the research literature on consumer emotion at home and abroad can be divided into five categories according to their research themes: dimension of consumer emotion (Wundt, 1896; H Schlosberg, 1954; Izzard, 1977; Russell, 1980 Plutchik, 1980; Edell, Burke, 1987; Huang Xiting, 2007), measurement of consumer emotion (KS Ryu, SCS Jang, 2007; HS Han, KS Ryu, 2009; C Homburg, WD Hoyer, N Koschate, 2005), consumer emotion for purchase or comment Impact (PD Bennett, GD Harrell, 1975; Sun Ying, Du Jiangang et al, 2014; Christopher J. White, 2010; Zhang Shengliang, Gao Huan, 2011;), the impact of consumer emotion on consumer decisionmaking (G Walters, B Sparks, C Herington2012) Huang Ling, 2007;), consumer emotion and the impact of customer satisfaction or customer loyalty (M Hume, GS Mort, 2010; Han Xiaowei, Wen Biyan, Wu Xiaoyu, 2004; Josee Bloemer, Ko de Ruyter, 1999 Du Jiangang, Fan Xiucheng, 2007;).

\section{B. Participation Behavior}

Individual behavior is an action that meets or does not conform to certain norms under the control of certain factors such as thought, cognition, and emotion. This is the individual's reflection on the nature of the environment, the characteristics of the social environment and its interaction with the environment. Individual behavior is influenced by internal factors such as personal physiological factors, psychological factors, cultural factors and economic factors, as well as the internal environment and external environment of the organization in which it is located. This is a complex process of behavior. Some scholars have analyzed the online community, and they explored user participation behavior from the perspectives of user-community relationship, user attitude, emotional connection, and involvement. For example, Algesheimer pointed out that the identity and perceived value of the brand community promoted user engagement. Shang (2006) argues that cognitive involvement has a significant impact on the potential participation behavior of the brand community, but has no significant effect on active participation (posting) behavior. Emotional involvement has no significant effect on potential and active participation behavior. Casaló (2010) focuses on online communities in which companies operate, and believes that attitudes, perceived behavioral controls, and perceived usefulness promote user engagement. Gharib (2017) focuses on the active participation of users in the B2B community and finds that emotional commitment and general reciprocity play a positive role.
The dimensions of user engagement behavior have been divided by many scholars from different angles. Foreign scholars D.S.P.Cermak and K.M.File (1994) suggest that user participation is a specific behavior related to the production and delivery of services, including the user's efforts and the degree of involvement. C. Claycomb (2001) mentioned that the role and role of users in services can be measured from three aspects: attendance, information provision, and co-production. R.V. Kozinet (1999), Y. Wang, and D.R. Fesenmaier (2004) suggest that user engagement behavior can be measured by duration of participation, frequency of participation, and level of participation. A.R. Hubbert (1995) further divided user participation into three levels: low, medium and high participation, depending on the degree of participation.

In recent years, domestic scholars have also analyzed user participation. Fan Xiaoping (2009) believes that the user participation level can be divided into four aspects: simple browsing (users browse freely, passively access information), active participation (users enthusiastically participate in activities initiated by others or discuss topics), organizational advocacy (including Initiate discussion topics, or plan activities, attract other members to participate, etc.) and project management (users become intermediaries between community members and community operators). Wang Xihe and Du Rong (2011) believe that the participation level of virtual community members is mainly reflected in the frequency of participation and the length of participation. Zhou Gang and Yan Lei (2016) pointed out that the level of contribution of members to the community reflects the level of participation. The greater the contribution rate of the user, the higher the level of participation. The deep participation behavior is characterized by members voluntarily making certain contributions in the process of participating in the community to solve problems. The shallow participation behavior mainly refers to browsing activities and posting activities.

\section{RESEARCH ASSUMPTION}

The consumption environment of Chinese residents has experienced a liquid consumption environment that is transformed from a physical consumption environment to a combination of entity and virtual. Consumer emotion in the virtual and real environment has been studied by many scholars in consumer decision-making and consumption behavior. For example, Mehrabian (1974) proposed a model of the relationship between emotional experience and behavior, and environmental stimuli and individual emotions (evoke, pleasure and dominance) have an associated behavioral response. Two experiments by MF Luce (1998) show that consumers can change their emotions by manipulating decision attributes. Consumers have the opportunity to choose to evade (maintain the status) to reduce their emotional level. And the more emotionally determined decision-making environment is associated with more avoidance options. Lazarus (1991) argues that from the perspective of evaluation theory, the consumer environment is accompanied by consumer-specific emotional responses. Emotional reactions are consumer responses to consumer events and the consumer environment. C Xie, RP Bagozzi and K Grønhaug (2015) studied the effects of moral emotion on corporate green and non-green behaviors, with individual characteristics as a moderator. The results show that 
for the company's non-green behavior, various individual differences (social justice values, empathy, moral identity, selfconcept) regulate negative moral emotions (contempt, anger, disgust), leading to negative reactions of consumers (negative word of mouth), complaining about behavior, resisting). For the green action of the company, empathy regulates positive emotions through gratitude, thus affecting the positive reaction of consumers (positive word of mouth, resisting negative information, identifying companies, investing).

The influence of consumer emotion on consumer behavior is a hot issue for domestic and foreign marketing scholars. JE Bigné, AS Mattila, L Andreu (2008) studied the relationship between emotions, consumer satisfaction and behavioral intentions in a hedonic service environment. The results show that happiness and satisfaction, loyal behavior are positively related. L Dubé, K Menon (2000) suggested that although positive emotions have a direct impact on customer satisfaction, negative emotions negatively affect consumer satisfaction only in the negative emotion of service providers. Negative emotions caused by reasons other than providers may be positively related to satisfaction. Different emotional experiences at a certain stage of the service also affect the consumer's own expression and behavior. A Pansari, V Kumar (2016) proposes a framework that describes the components of customer engagement behavior and the antecedents (satisfaction and emotions) and consequences (tangible and intangible outcomes) of customer engagement. Zhang Hui, Wang Tao, and Liu Hongshen (2011) believe that customer engagement behavior (cooperation level, relationship establishment, attendance interaction, etc.) will cause changes in customer psychology (control, emotion, etc.). Du Jiangang and Fan Xiucheng (2007) proposed a conceptual model of the impact of emotion on satisfaction and behavior. In the context of service recovery, the impact of emotion on consumer satisfaction is very significant, and it also directly affects the behavioral tendency of customers. Yang Yong, Ma Qinhai and others (2017) found that emotional labor (surface performance, deep performance and real expression) significantly positively affected customer participation behavior. Emotional value plays a full intermediary role in deep performance and customer participation behavior, real expression and customer participation behavior. So, make the assumption:

H1: Positive emotions negatively affect customer participation behavior

H2: Negative emotions positively affect customer engagement behavior

\section{CONCLUSION}

Many factors can trigger consumer sentiment during product consumption. Previous studies have focused on the relationship between consumer sentiment and satisfaction triggered by product attributes and store environments. Other factors (advertising, sales promotion, public relations, etc.) can also trigger consumer sentiment. Through the collation of existing research, it is not difficult to find that consumer emotion has a significant impact on user participation behavior. In different situations, the effect of user participation behavior is different according to the difference of consumer emotion.
Domestic scholars have done some research on this, but the depth and content of research need to be further explored. Therefore, based on the context of mobile social networks, this study explores the impact of consumer emotion on user participation behavior, which is not only a useful supplement to consumer emotions and user participation behavior theory, but also provides some inspiration for enterprises to use consumer emotion to stimulate users to participate in corporate activities.

There are three limitations in this study. First, this paper does not deeply explore the internal mechanisms and boundary conditions of consumer emotion affecting user participation behavior. Second, this study only confirms the influence of consumer emotion on user participation behavior from the theoretical level, but has not been empirically tested. Third, the paper does not divide the dimensions of consumer emotion and user participation behavior.

Therefore, in the subsequent research, empirical methods can be used to test whether the above theory holds. The internal mechanism of action can also be studied in depth.

\section{ACKNOWLEDGEMENT}

This study is supported by the National Natural Science Foundation of China(No.71562020) and the China Postdoctoral Science Foundation (No.2017M620532).

\section{REFERENCES}

[1] SHANG R, CHEN Y, LIAO H. The Value of Participation in Virtual Consumer Communities on Brand Loyalty.J. Internet Research, 2006, pp .398-418.

[2] CASAL L V, FLAVI N C, GUINALU M. Determinants of the Intention to Participate in Firmhosted Online Travel Communities and Effects on Consumer Behavioral Intentions.J. Tourism Management, 2010, pp.98911.

[3] GHARIB R K, PHILPOTT E, DUAN Y. Factors Affecting Active Participation in B2B Online Communities: An Empirical Investigation.J. Information\&Management, 2017, pp.:516-530.

[4] CERMAK D S P, FILE K M. Customer participation in service specification and delivery J.Journal of applied business research, 1994, pp.90-97.

[5] CLAYCOMB C, LENGNICK-HALL C A, INKS L W. The customer as a productive resource: a pilot study and strategic implications.J.Journal of business strategies, 2001, pp.47-68.

[6] KOZINETS R V. E-tribalized marketing? The strategic implications of virtual communities of consumption.J.European management journal, 1999, pp.252-264.

[7] WANG Y, FESENMAIER D R. Modeling participation in an online travel community. J.Journal of travel research, 2004,pp.261-270.

[8] HUBBERT A R. Customer co-creation of service outcomes: effects of locus of causality attributions.D.Phoenix:Arizona State University, 1995.

[9] Fan Xiaoping. Participation Motivation of Non-trading Virtual Community Members: Empirical Research and Management Enlightenment.J.Journal of Industrial Engineering and Engineering Management,2009, pp.1-6. (In Chinese)

[10] Wang Xixi, Du Rong. Research on the Influence of Interpersonal Trust and Self-efficacy on Knowledge Sharing and Participation Level of Virtual Community.J.Information Theory and Practice, 2011,pp.71-74, 92. (In Chinese)

[11] Zhou Gang, Pei Lei. An Empirical Study of Participant Behavior and Motivation in Tourism Virtual Community.J.The Press,2016,pp.61-68. (In Chinese) 
[12] Firat A F, Dholakia N. Consuming People: From Political Economy to Theaters of Consumption .M . London: Sage, 1998.pp. 542.

[13] Xie C, Bagozzi R P, Grønhaug K. The role of moral emotions and individual differences in consumer responses to corporate green and non-green actions.J. Journal of the Academy of Marketing Science, 2015, pp.333-356.

[14] Ridgway N M, Bloch P H, Dawson S. Shopping Motives, Transient Emotional States and Retail Outcomes.J. Journal of Retailing, 1990, pp.408-427.

[15] Phillips D M, Baumgartner H. The Role of Consumption Emotions in the Satisfaction Response.J. Journal of Consumer Psychology, 2002, pp.243-252.

[16] Pluctchik R. A Structural Model of the Emotions [A]. Emotion: A Phsychoevolutionary Synthesis .M. New York: Harper and Row Publishers, 1980. pp.155.

[17] Edgell S, Hetherington K, Warde A. Consumption Matters: The Production and Experience of Consumption .M. Oxford: Blackwel, 2003. pp.78- 153 .

[18] Holbrook M B. The Millennial Consumer in the Texts of Our Rimes: Experience and Entertainment.J. Journal of Macro Marketing, 2002, pp.178- 192.

[19] Csikszentmihalyi M. Flow: The Psychology of Optimal Experience .M. New York, NY: Hrper and Row, 2002. pp.341 - 363.

[20] Sheth J N. Psychobiology and Consumer Research: A Problem of Construct Validity .J. Journal of the Academy of Marketing Science, 1979, pp. 414 - 427.

[21] Unger L S, Kernan J B. On the Meaning of Leisure: An Investigation of Some Determinants of the Subjective Experience.J. Journal of Consumer Research, 1983,pp.381- 392

[22] Izard C E. Human Emotions.J. Emotions Personality \& Psychotherapy, 1977.

[23] Luce M F. Choosing to Avoid: Coping with Negatively Emotion-Laden Consumer Decisions.J. Journal of Consumer Research, 1998, pp.409433.

[24] Nyer P U. A study of the relationships between cognitive appraisals and consumption emotions .J. Journal of the Academy of Marketing Science, 1997, pp.296-304.

[25] Ladhari R. The effect of consumption emotions on satisfaction and word-of-mouth communications.J. Psychology \& Marketing, 2007, pp.1085-1108.

[26] Han Xiaowei, Wen Biyan, Wu Xiaoqi. The Influence of Customer Consumption Emotion on Customer Satisfaction.J. Nankai Management Review, 2004, pp.39-43. (In Chinese)

[27] Zhang Shengliang, Gao Huan. The impact of service remedies on consumer sentiment and behavioral intentions.J. Nankai Management Review, 2011, pp.37-43. (In Chinese)

[28] Du Jiangang, Fan Xiucheng. Dynamic Impact Mechanism of Multiple Emotional Infections on Consumer Negative Emotions in Service Consumption.J.2009, pp.346-356. (In Chinese)

[29] Chen Hui, Li Yuanzhi. Analysis of Factors Affecting Consumers' Purchase Decisions under E-commerce Conditions.J. Journal of Beijing University of Posts and Telecommunications(Social Sciences Edition),2007, pp.1-4. (In Chinese)

[30] Zhai Lihui, Chen Shuqing. A Review of the Relationship between Consumer Emotion and Post-Purchasing Behavior.J. Journal of Southwest Jiaotong University(Social Science Edition), 2006, pp.:93-99.

[31] Geng Guoxiang. Review of Consumer Emotion Research.J. Soft Science, 2008, pp.8-32. (In Chinese) 